\title{
Numerical Simulation of a Vortex Combustor Based on Aluminum and Steam
}

\author{
Xianhe Chen ${ }^{1}$, Zhixun Xia ${ }^{1, *}$, Liya Huang ${ }^{2}$ and Likun Ma ${ }^{1}$ \\ 1 Science and Technology on Scramjet Laboratory, National University of Defense Technology, \\ Changsha 410073, China; c_xianhe@foxmail.com (X.C.); malikun-2005@hotmail.com (L.M.) \\ 2 Department of Aerospace Science and Engineering, National University of Defense Technology, \\ Changsha 410073, China; huangly91@hotmail.com \\ * Correspondence: zxxia@nudt.edu.cn; Tel.: +86-731-84576450 \\ Academic Editor: Antonio Ficarella \\ Received: 10 October 2016; Accepted: 9 December 2016; Published: 16 December 2016
}

\begin{abstract}
In this paper we report a new development in the numerical model for aluminum-steam combustion. This model is based on the diffusion flame of the continuum regime and the thermal equilibrium between the particle and the flow field, which can be used to calculate the aluminum particle combustion model for two phase calculation conditions. The model prediction is in agreement with the experimental data. A new type of vortex combustor is proposed to increase the efficiency of the combustion of aluminum and steam, and the mathematical model of the two phase reacting flow in this combustor is established. The turbulence effects are modeled using the Reynolds Stress Model (RSM) with Linear Pressure-Strain approach, and the Eddy-Dissipation model is used to simulate the gas phase combustion. Aluminum particles are injected into the vortex combustor, forming a swirling flow around the chamber, whose trajectories are traced using the Discrete Phase Model (DPM). The simulation results show that the vortex combustor can achieve highly efficient combustion of aluminum and steam. The influencing factors, such as the eccentric distance of the inlet of aluminum particles, particle size and steam inlet diameter, etc., are studied.
\end{abstract}

Keywords: aluminum particle; steam; vortex combustor; diffusion flame; numerical simulation

\section{Introduction}

Aluminum is an important energetic component of many solid propellants, explosives, and pyrotechnic formulations, and is used as a new energy material since the aluminum-water reaction can produce hydrogen and form aluminum fuel cells [1]. In recent years, many aspects of the aluminum and water reaction were researched in aluminum-water ramjet and aluminum-water power systems such as Hybrid Aluminum Combustor (HAC) [2], or Hybrid Aluminum Combustor -Solid Oxide Fuel Cell (HAC-SOFC) [3,4] and the results shows that this system has high energy density. At present, the aluminum-water mixture is made into solid grains [5-8] by using the slow reaction characteristics of aluminum-water at low temperature, and the burning rate characteristics and the performance are analyzed. For undersea vehicles, the use of external water and its own carrying aluminum reaction can greatly improve the performance of the power system. Besides, the water ramjet engine using a similar ramjet principle was researched. Considering the fact that the aluminum and liquid water reaction is difficult, the water ramjet engine uses fuel-rich propellant, in general, in order to realize water aluminum combustion. However, by doing so, the aluminum content is reduced, and therefore the engine performance is decreased. Undoubtedly, if pure Al powder were used, the engine performance would be the highest. Because of a relatively high ignition temperature and a relatively long ignition delay times of aluminum-water combustion, an appropriately high temperature zone and appropriately long residence times within the combustor are required to ignite 
and react all of the aluminum. Therefore, the vortex combustor concept was proposed by Miller $[9,10]$ and experimental studies were carried out. In this design aluminum particles are injected into the vortex combustor and form a swirling flow around the chamber. Consequently, a suitably long residence times and proper high temperature ignition zone are established for particles. It is expected that with this vortex combustor, a high aluminum-water combustion efficiency can be achieved. However, there are no relevant research reports on the performance optimization and calculation of the vortex combustor.

According to the existing research, the combustion law of aluminum particles is basically based on the combustion experiments [11-17] of single particles and particle groups, and various particle size and burning time laws were obtained, such as $d^{1.8}$ and $d^{1.5}$. At the same time, there are many studies from the perspective of the mathematical model theory [14,18-22], whereby when the particle size of the aluminum particles is large, the combustion is controlled by the continuum regime, whereas, for the nano-aluminum particles, the combustion is controlled by the free-molecule regime, and when the particle size is between these two extremes, the combustion is controlled by a transition regime. In the calculation of the current flow field of aluminum particles, basically the burning time change law ( $d^{\mathrm{n}}$ law) of aluminum particles obtained by experiments is adopted. However, this law only reflects the change of particle burning time with particle size, but cannot accurately describe the particle size change process with time, so there are some limitations in the calculation results.

According to the previous research, this paper draws on the research ideas of the gas flame from Mohan [19], with the existence of flames on the surface of aluminum particles assumed. Under the condition of thermal equilibrium between the particle and the flow field, a simplified combustion model of aluminum particles is obtained, which can be used for the calculation of the two-phase flow of aluminum particles and distribution for the complete particles' combustion process. The results for this model are verified when compared with the experiment results. At the same time, the vortex combustor is designed according to the vortex combustor concept proposed by Miller, and the simulation calculations are carried out. Besides, the aluminum water chamber performance under the condition of the different aluminum particle size, steam temperature, aluminum water mass ratio and vortex combustor configuration are obtained.

\section{Physical and Numerical Model}

\subsection{Physical Model}

A vortex combustor which contains four circumferential steam inlets and four circumferential aluminum particles inlets are proposed according to the vortex combustor concept of Miller [9], seen in Figure 1. To make sure that the aluminum particles are heated and ignited completely, the swirl chamber has a recessed cavity configuration. In order to facilitate the mesh generation, the configuration doesn't use completely tangent inlet conditions, but an eccentric design instead. According to the calculation results, the particles' velocity is about $40 \mathrm{~m} / \mathrm{s}$, which means the centrifugal force is about 2000 times as much as gravity, so gravity is not considered. To reduce the computational cost, only a quarter of the combustor is simulated with periodic boundary conditions.

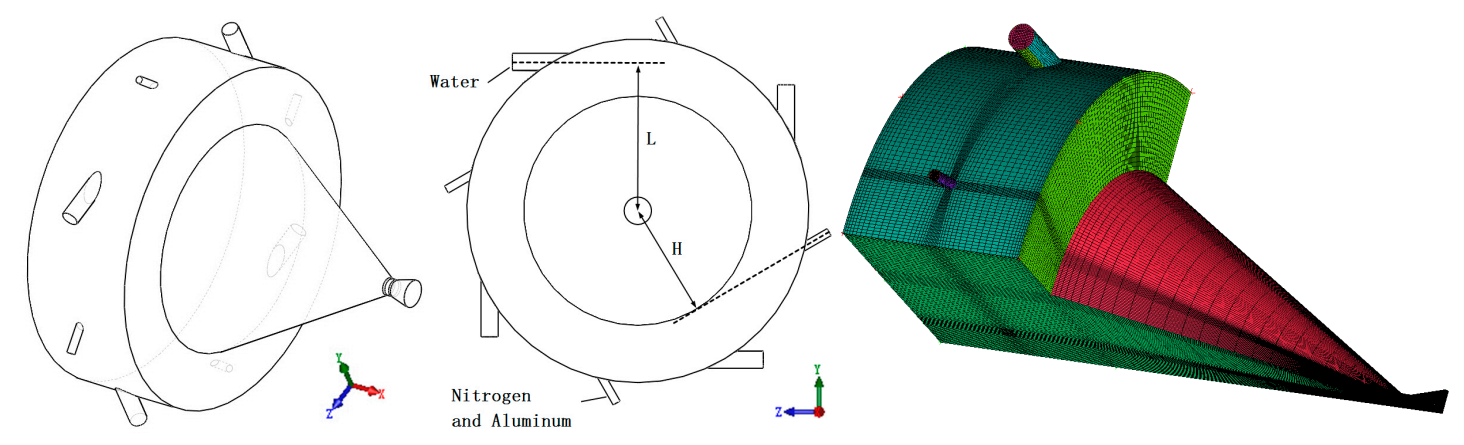

Figure 1. Vortex combustor configuration diagram. 


\subsection{Numerical Models and Boundary Conditions}

In consideration of the existence of a strong swirl flow field in the vortex combustor, the turbulence effects are modeled using the Reynolds-Stress Model (RSM) with Linear Pressure-Strain approach. Meanwhile, Eddy-Dissipation model is used to simulate the gas phase combustion and the simulations are carried out under steady state conditions.

If there is no special declaration, in all cases, the chamber diameter is $150 \mathrm{~mm}$, the length is $50 \mathrm{~mm}$, the cavity height is $25 \mathrm{~mm}$, the eccentric distance of the steam inlet $L=65 \mathrm{~mm}$, the eccentric distance of the aluminum particle inlet $H=30 \mathrm{~mm}$, the steam mass flow rate is $4 \times 5 \mathrm{~g} / \mathrm{s}$ [10], steam temperature is $750 \mathrm{~K}$, the aluminum mass flow rate is $4 \times 4 \mathrm{~g} / \mathrm{s}$, Nitrogen mass flow rate is $4 \times 2 \mathrm{~g} / \mathrm{s}$, particle diameter is $10 \mathrm{um}$, the diameter of the steam inlet $D=6 \mathrm{~mm}$, the diameter of the Nitrogen inlet is $3 \mathrm{~mm}$, the nozzle throat diameter is $6 \mathrm{~mm}$. The wall is set to the adiabatic boundary condition and it is assumed that the particles will be trapped when colliding with the wall if in the liquid state.

\subsection{Aluminum Particle Combustion Model}

Because the aluminum particle burning time correlations from experiments (such as the law of $d^{1.8}$ ) only reflect the changes of particle burning time with particle size, but cannot accurately describe the particle size change process with time, taking into account the use of micron-sized aluminum particles in this paper, the diffusion control of the continuum regime is adopted instead.

For diffusion-controlled conditions, the particle mass consumption rate are given by [23]:

$$
\frac{\dot{m}}{4 \pi r^{2}}=\frac{\rho D_{o x}}{r} \ln \left(1+i Y_{O, \infty}\right)
$$

Considering that the alumina cap will have a certain effect on the combustion of particles, the relationship among the particle mass change, the effective surface area and the particle radius can be obtained in the flow field:

$$
\dot{m}=\frac{\rho S_{A l} \boldsymbol{D}_{o x}}{r} \ln \left(1+i Y_{O, \infty}\right)
$$

The diffusivity of gases is given by [23]:

$$
D_{\mathrm{ox}}=\frac{2}{3}\left(\frac{k_{B}^{3} T N_{A}}{\pi^{3} M W}\right)^{1 / 2} \frac{T}{\sigma^{2} p}
$$

The oxide caps of the aluminum droplets grow as the droplets collide and agglomerate with the other oxide particles. This collision process is driven by the relative velocity between the particle and the surrounding alumina. The model of alumina deposition is given by [24]:

$$
\frac{d m_{d e p}}{d t}=\frac{\pi}{16} r^{2}\left|\mathbf{u}_{p}-\mathbf{u}_{g}\right| C_{s} \eta_{c}
$$

The view of most of the aluminum particle ignition theories $[16,17,25,26]$ is that the particle ignites successfully when the particle temperature reaches the rupture temperature of the oxide layer. The ignition temperature $[14,27]$ is obtained by fitting the experimental data under different particle sizes. The fitting formula is $T_{i g}=1366.4+205.97673 \ln (d+0.24173)$.

The combustion of aluminum particles can be divided into four stages: the particle heating, the particle melting, the particle ignition to give the alumina cap form, and the particle burning. Due to the fact that $B i=h \boldsymbol{D}_{p} / k_{p}<0.01$, it is assumed that the particle temperature is uniform but time varies. The heat exchange between the particle and the environment is through convection heat transfer, radiation heat transfer, chemical reaction heat, latent heat of vaporization and condensation heat and so on. A model for $S_{A l}$ as illustrated in Figure 2, is proposed in Melcher [21]:

$$
h^{3}-3 r h^{2}+\frac{3 V}{\pi}=0
$$




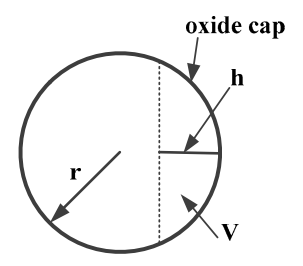

Figure 2. Model of oxide deposition on the aluminum particle surface.

\subsubsection{Stage I: Particle Heating}

This stage is finished before the melting of aluminum particles, with the aluminum surface initially covered with a layer of oxide, seen in Figure 3.

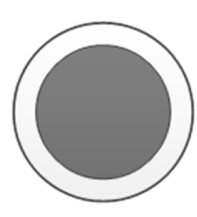

Stage I (particle heating)
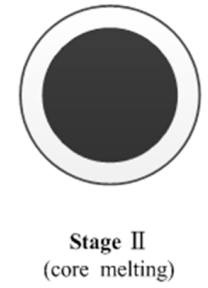

$\square \mathrm{Al}_{2} \mathrm{O}_{3}(\mathbf{s})$

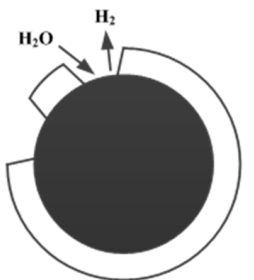

Stage III

(the oxide layer cracking, ignition and combustion)

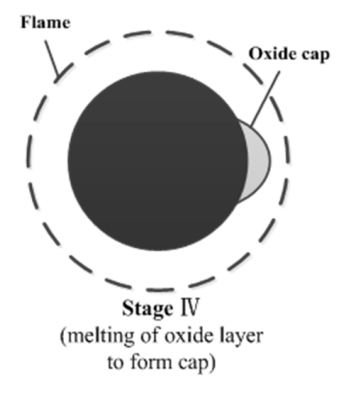

Al(I)

Figure 3. Configuration showing an $\mathrm{Al}$ particle ignition and combustion procedure.

According to the conclusions of the literature, the thickness of the oxide layer is generally between $2 \mathrm{~nm}$ and $4 \mathrm{~nm}$ [28]. A $4 \mathrm{~nm}$ thickness is used in this paper. Assuming the heating process is quick, with no chemical reactions taking place, the heat exchange of particle includes the convection heat $\dot{Q}_{c o n v}$, radiation heat $\dot{Q}_{\text {rad }}$ and condensation heat $\dot{Q}_{\text {cond }}$ :

$$
m_{p} c_{p} \frac{d T_{p}}{d t}=\dot{Q}_{c o n v}+\dot{Q}_{\text {rad }}+\dot{Q}_{\text {cond }}
$$

where:

$$
\begin{gathered}
\dot{Q}_{\text {conv }}=A_{p} \rho \frac{v_{g} C_{P_{g}}}{P r_{g}}\left(T_{g}-T_{p}\right) N u_{p} \\
\dot{Q}_{\text {rad }}=\varepsilon_{p} k_{B} A_{p}\left(T_{g}^{4}-T_{p}^{4}\right) \\
\dot{Q}_{\text {cond }}=m_{\text {dep }}\left(h\left(T_{p}\right)-h\left(T_{g}\right)\right)
\end{gathered}
$$

\subsubsection{Stage II: From Aluminum Particle Melting to Particle Ignition}

The phase of the aluminum is liquid, alumina is a solid and particle size is unchanged. Assuming that there is no chemical reaction taking place too. $\dot{Q}_{\text {phase, } A l}$ is the phase transformation heat:

$$
m_{p} c_{p} \frac{d T_{p}}{d t}=\dot{Q}_{c o n v}+\dot{Q}_{\text {rad }}+\dot{Q}_{\text {phase }, A l}+\dot{Q}_{\text {cond }}
$$

\subsubsection{Stage III: From Ignition of Aluminum Particles to Alumina Melts}

In this stage, the expansion of the liquid aluminum enlarges the particle size, resulting in the oxide layer rupture, and the aluminum particles start to ignite and burn. The thermal characteristics 
of this stage show that the exposed aluminum oxidation reaction with water produces the heat used for heating the aluminum core and alumina. The oxide layer grows until the aluminum oxide is fully melted, which indicates the end of this stage. $\dot{Q}_{\text {phase }, A l_{2} \mathrm{O}_{3}}$ is the alumina melting heat. The exposed aluminum particle surface area $S_{A l}$ is equal to the surface area of the aluminum particle surface area $S$ minus the internal surface area of initial oxidation layer $S_{\text {init }}$. When the temperature reaches the melting point of aluminum oxide, $S_{A l}$ is equal to the greater one of these values and the area from Equation (6). In this stage, when $S_{A l} \leq 0$, the aluminum particles extinguish:

$$
\begin{gathered}
m_{p} c_{p} \frac{d T_{p}}{d t}=\dot{Q}_{\text {conv }}+\dot{Q}_{\text {rad }}+\dot{Q}_{\text {comb }}+\dot{Q}_{\text {phase, }, \mathrm{Al}_{2} \mathrm{O}_{3}}+\dot{Q}_{\text {cond }} \\
S_{A l}=S-S_{\text {init }}
\end{gathered}
$$

2.3.4. Stage IV: Alumina Melts Completely and Forms an Alumina Cap on the Surface of the Particles, and Aluminum Particles Produce the Gas Phase Combustion Flame

This stage can be divided into two states.

1. Gas phase flames exist on the particle surface. When the particle temperature is lower than the boiling point of aluminum, if the reaction heat release is greater than the heat released by the particles to the surrounding environment, a gas phase flame exists on the surface of the particle. With the assumption that the reaction mass fraction of aluminum that reacts at the particle surface is $\alpha$, when the particle temperature reaches the boiling point of aluminum, combustion is pure gas phase combustion and $\alpha=0$. Due to the presence of a flame on the surface of the particles, the heat exchange between the particles and the surrounding environment is considered as a heat exchange between the flame and the environment, and this part of the energy is not taken into account in the calculation of the temperature change of the particle itself. $S_{A l}$ is calculated by Equation (6):

$$
m_{p} c_{p} \frac{d T_{p}}{d t}=\alpha \dot{Q}_{c o m b}+\dot{Q}_{c o n d}
$$

2. There is no gas phase flame on the particle surface. If the reaction heat release is lower than the one of particles to the surrounding environment, then $\alpha=1$, which means that only the particle surface oxidation reaction happens, and no flame exists on the particle surface. The heat exchange between the particle and the environment has to be considered in this situation:

$$
m_{p} c_{p} \frac{d T_{p}}{d t}=\dot{Q}_{c o n v}+\dot{Q}_{\text {rad }}+\dot{Q}_{c o m b}+\dot{Q}_{c o n d}
$$

Besides, when the oxidant concentration is 0 and the external environment temperature is greater than the particle temperature, the particles' combustion is controlled by the evaporation mechanism, and the particle temperature is maintained at the boiling point.

Taking into account the use of the diffusion control of the continuum regime, the model proposed in this paper is only applicable to the combustion of micro-aluminum particles. Besides, this model is only suitable for the combustion of aluminum particles in a single oxidant environment, and water is used as the oxidant in this paper. The combustion of nano-aluminum particles and the combustion of aluminum in a variety of oxidant environments will be studied in the future.

\subsection{Particle Motion}

The aluminum particles are tracked in a Lagrangian way. The trajectory of aluminum particles in the flow field is traced by a stochastic trajectory model. In the plane rectangular Descartes coordinate system, the influence of the random velocity of the gas phase on particle motion is not considered. The governing equations for the particle are:

$$
\frac{d x_{p}}{d t}=\mathbf{u}_{p}
$$




$$
\begin{gathered}
\frac{d \mathbf{u}_{p}}{d t}=\mathbf{F}_{p}+\mathbf{F} \\
\mathbf{F}_{p}=\frac{3}{4} \frac{C_{D} \rho}{\rho_{p} d}\left(\mathbf{u}_{g}-\mathbf{u}_{p}\right)\left|\mathbf{u}_{g}-\mathbf{u}_{p}\right|
\end{gathered}
$$

The drag coefficient of particles $C_{D}[29]$ is:

$$
\begin{gathered}
C_{\boldsymbol{D}}=\left\{\begin{array}{r}
24\left(1+\operatorname{Re}_{p}^{2 / 3} / 6\right) / \operatorname{Re}_{p} \text { for } \operatorname{Re}_{p} \leq 1000 \\
0.424 \text { for } \operatorname{Re}_{p}>1000
\end{array}\right. \\
\operatorname{Re}_{p}=\frac{d\left|\mathbf{u}_{g}-\mathbf{u}_{p}\right|}{v_{g}}
\end{gathered}
$$

\section{Results and Discussion}

\subsection{Aluminum Combustion Model Validation}

The calculated results using the aforementioned model as well as some of the earlier results [11] and correlations are shown in Figure 4. The large error bars account for the width of the size distributions for the sieved powders.

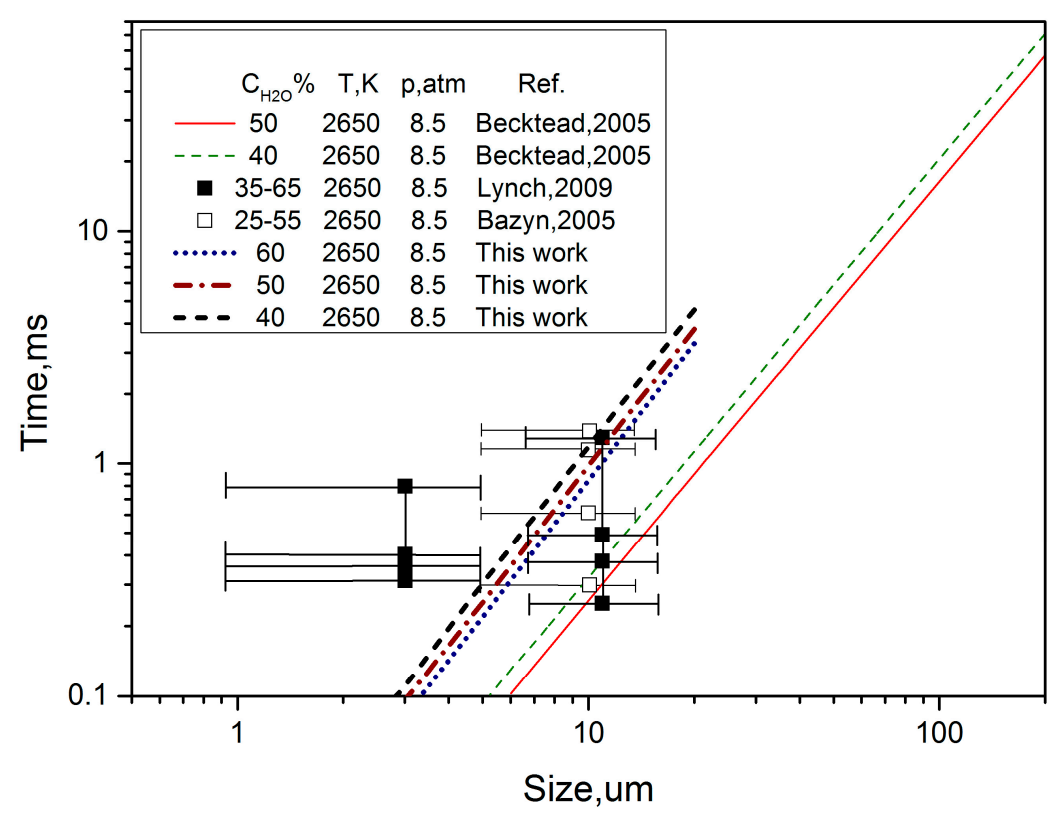

Figure 4. Combustion time as a function of particle size for $\mathrm{Al}$ particles.

According to Figure 4, the burning time is slightly larger than the results of Becktead, and between the results of Lynch and Bazyn, indicating that this model can better respond to the combustion variation law of aluminum particles. In addition, the model shows good results for particle sizes $>5 \mathrm{~ms}$. Since the model considers the effect of the initial oxidation layer and alumina cap, and as the real aluminum particle surface area was replaced by an effective area when calculating the particle mass change, there is a certain deviation between the calculated values and the experimental values. For particles smaller than $5 \mu \mathrm{m}$, the diffusion control of the continuum regime may not be applicable, thus this model does not use it.

Figure 5 shows the change of the temperature and the particle mass ratio of 10 micron aluminum particles when the ambient temperature is $2650 \mathrm{~K}$, pressure is $8.5 \mathrm{~atm}$, water mole fraction is 0.5. According to the results, the change of temperature is consistent with the model. In Stage I, the particles are heated up to their melting point, then the aluminum melts completely; 
in Stage II, particles are continuously heated up to the aluminum ignition temperature. In Stage III, after the successful ignition, under the condition of reaction heat and ambient heat exchange, the particle temperature quickly climbs to the alumina melting point. Due to the release of a large amount of heat, the alumina melts rapidly. In Stage IV, with the surface reactions and gas phase combustion, the particle temperature reached the aluminum boiling point, and ultimately a gas-phase flame forms. The value of $\alpha$ affects the process of the particle temperature change from alumina melting to the final gas phase flame. The smaller the $\alpha$, the smaller the surface reaction heat, and the slower of the temperature rise rate, but the temperature rise rate is almost constant after $\alpha>0.3$. Similarly, after $\alpha$ is more than 0.3 , the combustion time remained essentially unchanged. It can be known that when $\alpha$ is greater than 0.3 , one can get a relatively stable particle combustion variation law, so the following calculations takes $\alpha=0.3$.

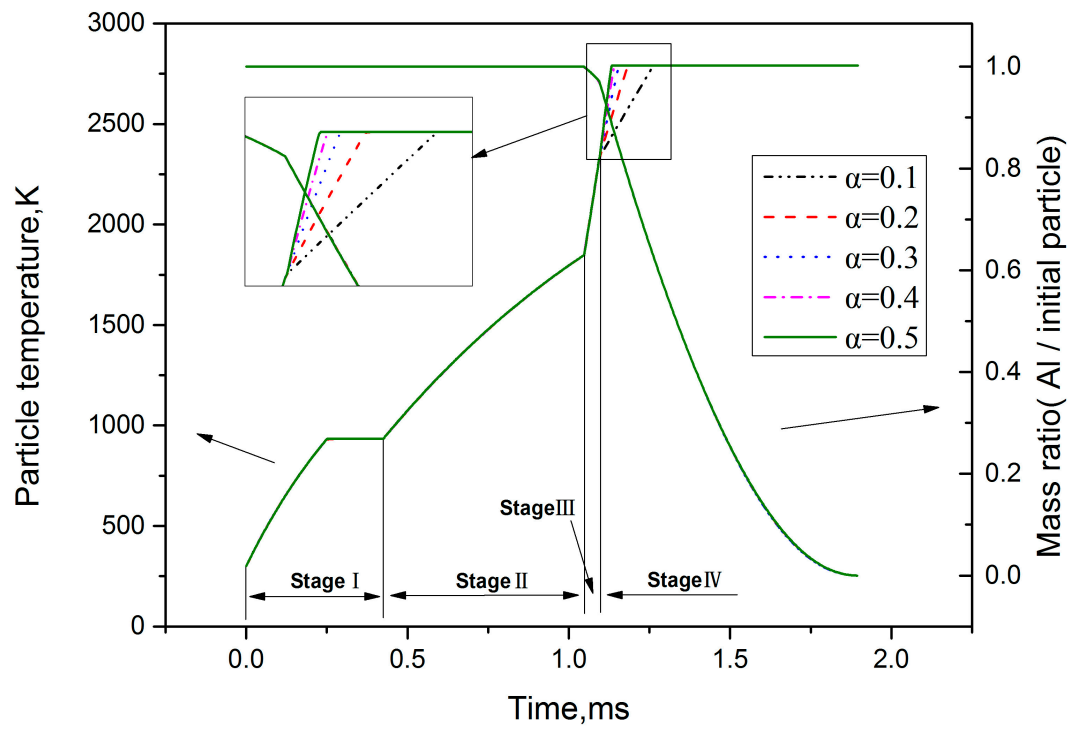

Figure 5. Particle temperature and mass ratio as a function of combustion time for $\mathrm{Al}$ particles.

\subsection{Flow Field Analysis}

Figure 6 shows the temperature field distribution. The final temperature is about $3170 \mathrm{~K}$, and this value is in agreement with the thermodynamic calculation results $(3175 \mathrm{~K})$. Figures $6 \mathrm{a}, 7$ and 8 show that the low temperature areas are mainly distributed in the periphery and near the steam and aluminum particle inlet. However, the high temperature area is mainly located inside the cavity structure, which means the cavity region is the main combustion zone (Figure 7). According to the configuration, the steam is approximately tangential to the entrance of the combustion chamber to form a swirl flow firstly, and then moves from outside to inside, and finally flows out of the combustion chamber, so the steam mainly exists in the cavity region too (Figure 8). When the aluminum particles enter the combustion chamber, they also form a swirl flow with the airflow, so the residence time of aluminum particles in the combustion chamber is longer, and this facilitates the combustion. Figure $6 \mathrm{~b}$ shows the high temperature region tends to burn in the front-end, indicating that most of the aluminum particles tend to rotate in the front-end of the combustion chamber. Figure $6 \mathrm{c}$ shows the $x=25 \mathrm{~mm}$ section complete temperature distribution. According to the ignition temperature of aluminum particles, the ignition temperature of 10 micron aluminum particles is about $1846 \mathrm{~K}$, while the figure shows that the temperature in most parts of the combustion chamber is greater than $2050 \mathrm{~K}$, which is convenient for the ignition of aluminum particles. 


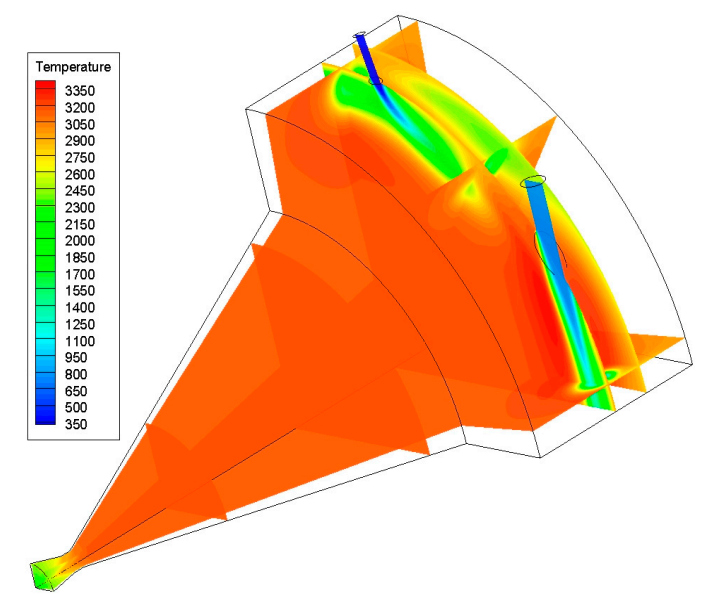

(a)

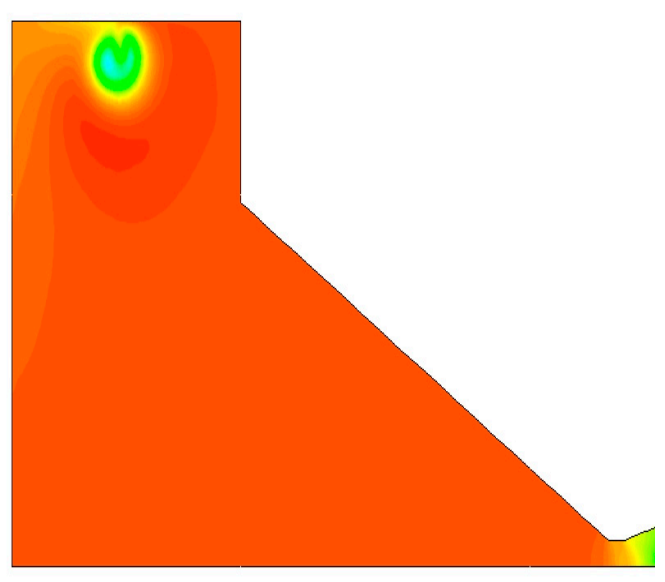

(b)

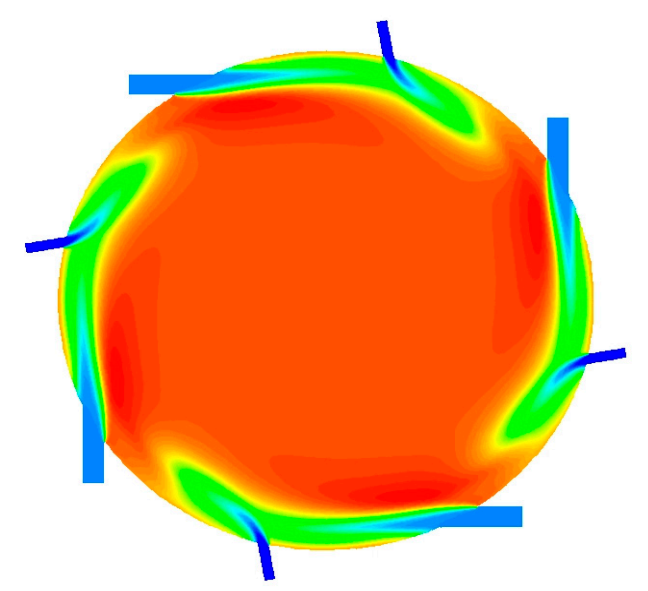

(c)

Figure 6. Temperature distribution. (a) 3D; (b) $\mathrm{y}=0 \mathrm{~mm}$; (c) $x=25 \mathrm{~mm}$.

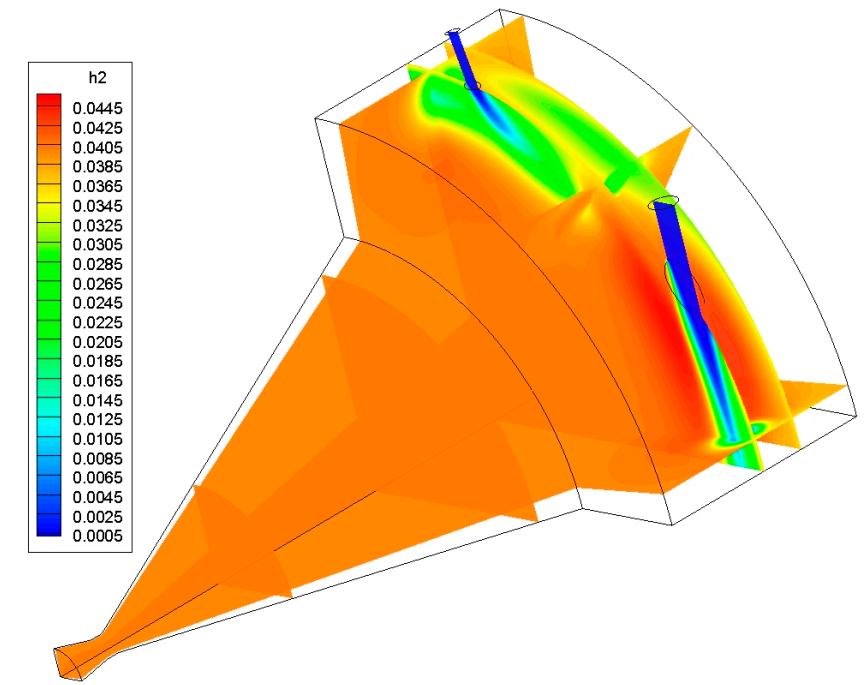

Figure 7. Hydrogen mass fraction distribution. 


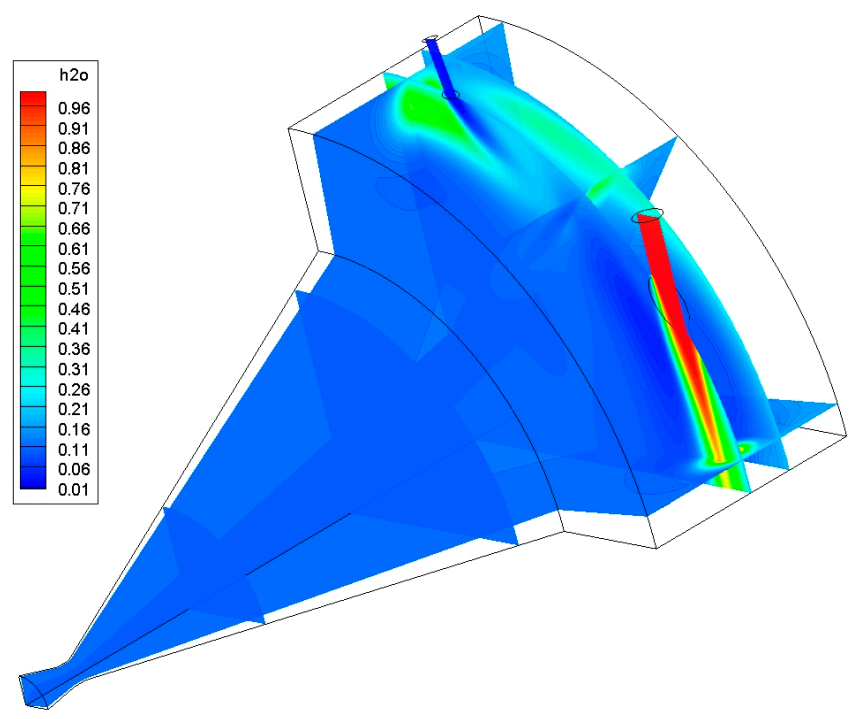

Figure 8. Water mass fraction distribution.

Figures 9 and 10 show the distributions of $\mathrm{Al}$ particle ignition delay time and burning time, respectively. In this case, the average ignition delay time of the aluminum particles is equal to $2.678 \mathrm{~ms}$ and the average burning time is equal to $1.726 \mathrm{~ms}$, which is longer than the burning time of single aluminum particle combustion (the burning time is about $1.5 \mathrm{~ms}$ when the concentration of oxidant and the pressure are $0.6 \mathrm{MPa}$ and $1.8 \mathrm{MPa}$, respectively). However, combustion time of most of the particles is within $2 \mathrm{~ms}$, and the ignition delay time is less than $3.5 \mathrm{~ms}$. The main reason is that in the combustion chamber, with the burning of aluminum particles, the $\mathrm{H}_{2} \mathrm{O}$ is gradually consumed and the $\mathrm{H}_{2} \mathrm{O}$ mass fraction distribution is inhomogeneous, resulting in a different distribution of the aluminum particles' burning time. The particle residence time in the chamber is equal to the ignition delay time plus the burning time, which shows that the residence time of most of the aluminum particles is less than $5.5 \mathrm{~ms}$.

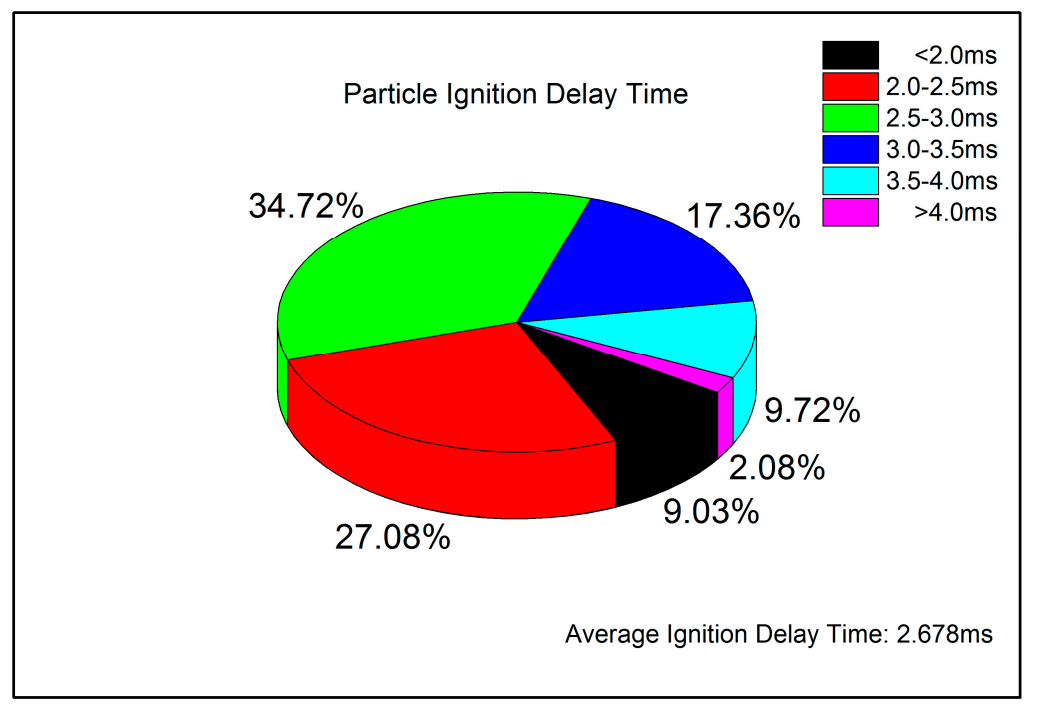

Figure 9. Ignition delay time distribution of $\mathrm{Al}$ particles. 


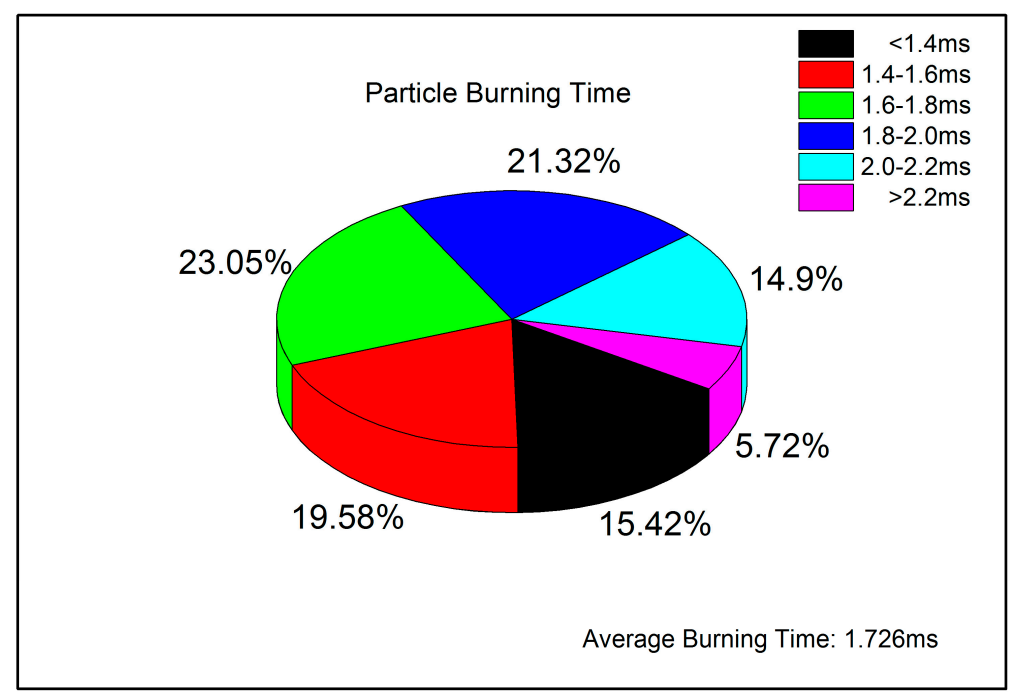

Figure 10. Burning time distribution of $\mathrm{Al}$ particles.

The trap ratio $\eta_{\text {trap }}$ is defined as the percentage of aluminum particles trapped by the combustion chamber wall before combusting completely:

$$
\eta_{\text {trap }}=N_{\text {trap }} / N_{\text {total }}
$$

The combustion efficiency can be calculated as:

$$
\eta=\frac{\Delta m_{A l}}{m_{A l}}=\frac{2 M_{A l} \Delta m_{\mathrm{H}_{2} \mathrm{O}}}{3 M_{\mathrm{H}_{2} \mathrm{O}} m_{A l}}=\frac{2 M_{A l}\left(m_{\mathrm{H}_{2} \mathrm{O}, \text { in }}-m_{\mathrm{H}_{2} \mathrm{O}, \mathrm{out}}\right)}{3 M_{\mathrm{H}_{2} \mathrm{O}} m_{A l}}
$$

According to the statistics of this case, the ratio of trapped of aluminum particles is about $5.72 \%$, and the total combustion efficiency is about $97.87 \%$. It can be found that, under the given initial conditions, the combustion of aluminum particles has a high combustion efficiency in this vortex combustor.

\subsection{Effects of Eccentric Distance of the Inlet of Aluminum}

According to the combustion chamber configurations, when the eccentric distance $\boldsymbol{H}$ different, the location of the aluminum particles in the combustion chamber is not the same, so the aluminum particle combustion effect is not the same, so in this section $H$ values of $70 \mathrm{~mm}, 50 \mathrm{~mm}, 30 \mathrm{~mm}$ and $0 \mathrm{~mm}$ are taken to see the effect on the combustion process of aluminum particles. In order to facilitate the data analysis, the parameters of the $x=25 \mathrm{~mm}$ cross section and the circumferential $45^{\circ}$ line are taken as the representative values.

Table 1 shows that with the increase of $\boldsymbol{H}$, the combustion efficiency, chamber pressure and particle burning time increase first and then decrease, however, the particle trapping efficiency increases gradually. On one hand, in the case of the same primary particle size, the gas velocity increases (see Figure 11) with the increase of $\boldsymbol{H}$, thus the greater centrifugal force may cause the particles to move toward the periphery of the combustion chamber, which causes the particles to be trapped on the wall, and the combustion efficiency is reduced. On the other hand, with the increase of $\boldsymbol{H}$, the particle are closer to the wall when they enter combustion chamber, which means the collision probability of particles with the walls could improve, resulting in a decrease of combustion efficiency. In addition, the particles' average burning time increases first and then decreases with the increase of $\boldsymbol{H}$. This is because the combustion efficiency increases first and then decreases with the increase of $\boldsymbol{H}$, and the concentration of steam decreases first and then increases (see Figure 11), which leads to decreases of the particle burning rate at first and then an increase. Therefore the particle average burning time increases first and then decreases. 
Table 1. Calculation result parameter distribution.

\begin{tabular}{ccccc}
\hline Parameter & $\boldsymbol{H - 0}$ & $\boldsymbol{H - 3 0}$ & $\boldsymbol{H - 5 0}$ & $\boldsymbol{H - 7 0}$ \\
\hline Pressure/MPa & 1.85 & 1.86 & 1.85 & 1.54 \\
Average burning time/ms & 1.626 & 1.726 & 1.728 & 1.416 \\
Trapped efficiency/\% & 3.76 & 5.72 & 8.33 & 38.78 \\
Combustion efficiency/\% & 96.81 & 97.87 & 96.29 & 70.50 \\
\hline
\end{tabular}

Figure 12 shows that the temperature distribution is basically consistent for $\boldsymbol{H}-0, \boldsymbol{H}-30$ and $\boldsymbol{H}$-50, and the difference among them is that the highest temperature decreases as $H$ increases. Meanwhile, the temperature decreases rapidly for $\mathbf{H}-70$. This is because the combustion efficiencies are basically consistent for $\boldsymbol{H}-\mathbf{0}, \boldsymbol{H}-30$ and $\boldsymbol{H}-50$, and the combustion efficiency is only $70.5 \%$ in $\boldsymbol{H}-70$. From the velocity curve in Figure 11, we can know that the velocity increases with the increase of $\boldsymbol{H}$ in most regions. The main reason is that with the increase of $\boldsymbol{H}$, the tangential velocity increases, so the velocity on this line is also increased.

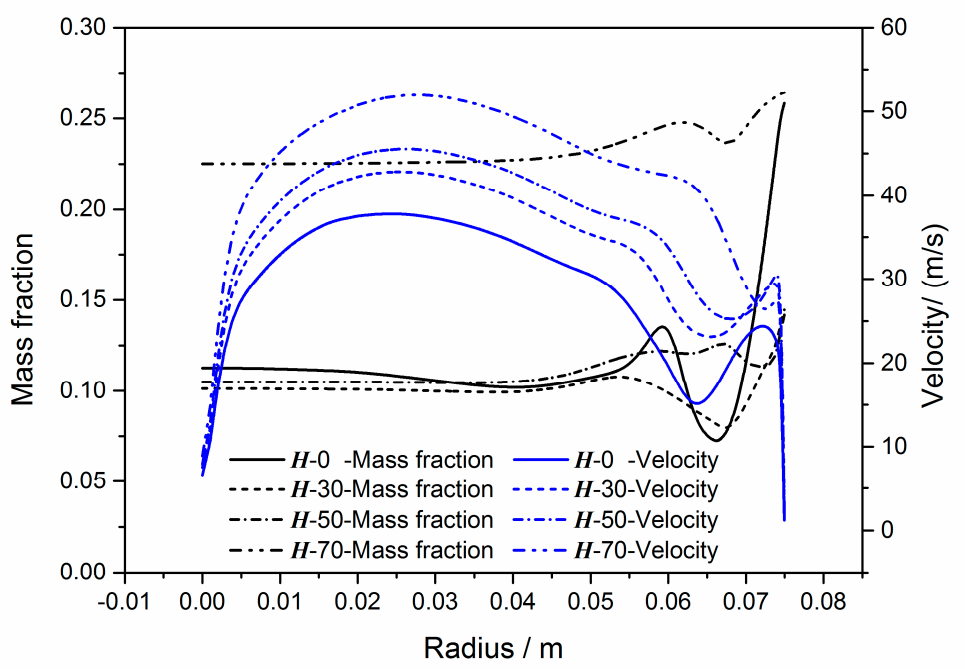

Figure 11. Velocity and $\mathrm{H}_{2} \mathrm{O}$ mass fraction distribution.
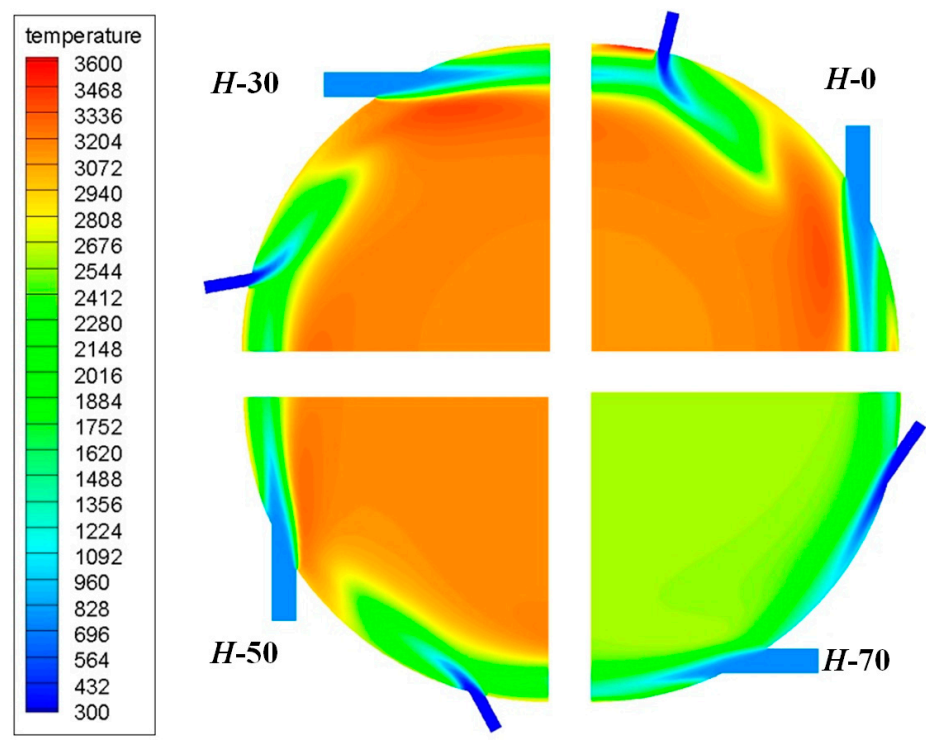

Figure 12. Temperature distribution. 


\subsection{Effects of Particle Size}

The diameters of the particles are set at 5, 10, 15, 18, 19 and $20 \mu \mathrm{m}$, respectively. As shown in Figure 13, as the particle size increases, the combustion efficiency decreases gradually, and the reduction rate increases gradually; finally in the particle size range of $18.5 \mu \mathrm{m}$ to $19 \mu \mathrm{m}$ a step appears, which means when the particle size is larger than $19 \mu \mathrm{m}$, aluminum particles can't maintain combustion. This means when the particle size is large enough, the combustion efficiency reaches a critical value, and when the combustion efficiency is lower than this value, the aluminum particles will not be able to sustain combustion. According to the burning time curve, the burning time increases with the increase of particle size. According to the configuration of the combustion chamber, the aluminum particles enter the combustion chamber at an angle and rotate with the gas flow. Similar to the principle of the cyclone separator, the particles with gas rotate from outside to inside and finally are exhausted from the combustion chamber. When the particle size is smaller, the aluminum particles easily ignite because of the high temperature of the combustion chamber, and the majority of the particles are burned before any collisions between the particle and the wall can occur, and the combustion efficiency is high. When the particle size is large, the particle ignition delay time increases. Under the influence of centrifugal force and resistance factors, successfully ignited particles are trapped before burning completely or most of them are not completed combusted, so the combustion efficiency decreases, leading to a further reduction of the combustion chamber temperature, and the ignition delay time continues to increase, the combustion efficiency continues to decline, which ultimately makes the aluminum particles not ignite, and the aluminum particles will not be able to maintain combustion.

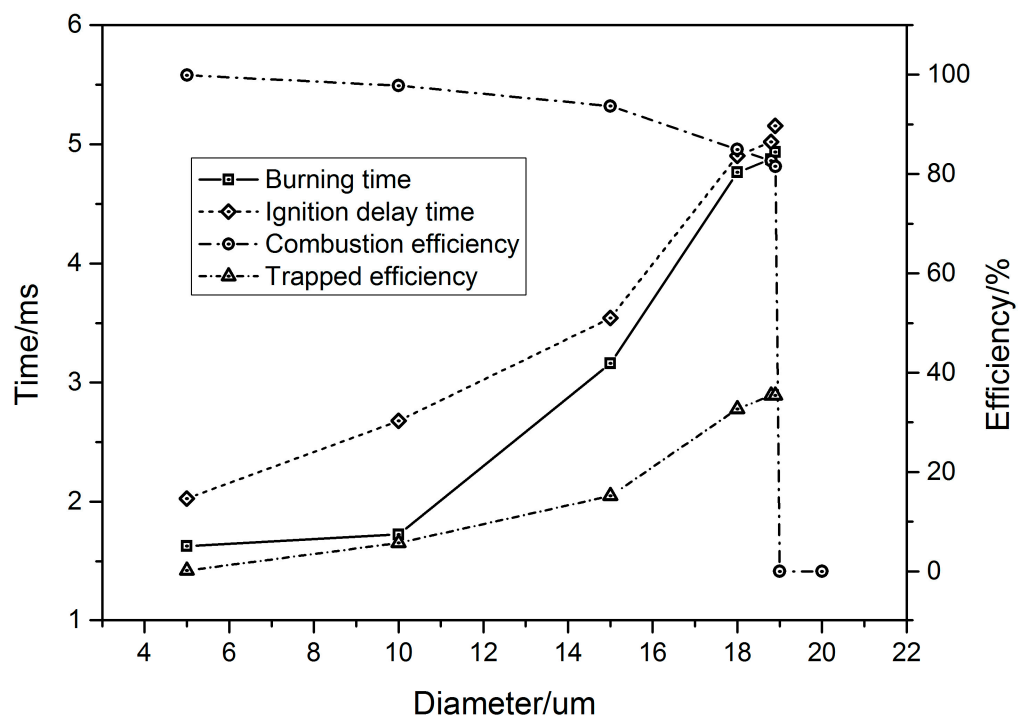

Figure 13. Distribution of combustion efficiency, ignition delay time, burning time and trapped efficiency for different particle sizes.

\subsection{Effects of Steam Inlet Diameter}

This section uses different steam inlet diameters $D=4,5,6$ and $7 \mathrm{~mm}$, respectively. According to the results in Table 2, with the increase of $\boldsymbol{D}$, the combustion chamber pressure, burning time and combustion efficiency increase while the trapped efficiency decreases. It can be known that the larger inlet steam diameter can improve the combustion efficiency of aluminum particles. According to Figure 14 , with the increase of $\boldsymbol{D}$, the gas velocity in the chamber decreases. Under the condition of the same particle size of aluminum particles, the lower gas velocity makes the aluminum particles' speed lower. A larger $\boldsymbol{D}$ means a longer running time for the aluminum particles, and before the aluminum particles collide with the wall or flow out of the combustion chamber, there is sufficient time to achieve particle combustion. Therefore, with the increase of $\boldsymbol{D}$, the combustion efficiency increases while the 
trapped efficiency decreases. However, with the increase of combustion efficiency, the mass fraction of $\mathrm{H}_{2} \mathrm{O}$ in the flow field decreases, and the combustion time of aluminum particles is shortened according to the law of the combustion of aluminum particles.

Table 2. Calculation result parameter distribution.

\begin{tabular}{ccccc}
\hline Parameter & $\boldsymbol{D}-\mathbf{4}$ & $\boldsymbol{D}-\mathbf{5}$ & $\boldsymbol{D}-\mathbf{6}$ & $\boldsymbol{D}-\mathbf{7}$ \\
\hline Pressure/MPa & 1.57 & 1.76 & 1.86 & 1.88 \\
Average burning time/ms & 1.369 & 1.679 & 1.726 & 1.895 \\
Trapped efficiency/\% & 38.23 & 10.54 & 5.72 & 3.196 \\
Combustion efficiency/\% & 71.62 & 95.55 & 97.87 & 98.84 \\
\hline
\end{tabular}

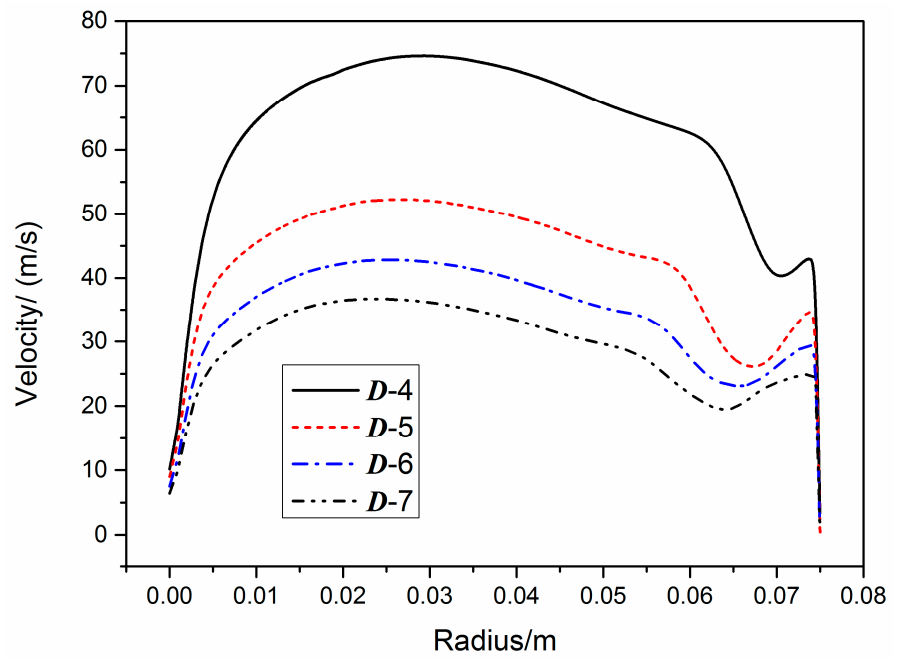

Figure 14. Velocity distribution curve.

\section{Conclusions}

An aluminum particle combustion model was established based on the continuum regime flame diffusion model and the thermal equilibrium between the particles and the flow field. This model could be used in the simulation of the aluminum particle combustion in two-phase flow. At the same time, the influence of the initial oxidation layer, alumina cap and the alumina deposition on combustion were considered.

A vortex combustor was designed, and the flow field structure parameters were obtained. The results show that this vortex combustor could achieve a relatively high efficiency for aluminum and water combustion.

The influences of different eccentric distances of the aluminum particle inlet, aluminum particle size and the steam inlet diameter on the performance of the combustion chamber were analyzed. With the increase of the eccentric distance of the aluminum inlet, the combustion efficiency, chamber pressure and particle burning time increase first and then decrease. However, trapped particle efficiency increases gradually. As particle size increases, the combustion efficiency decreases gradually, and the reduction rate increases gradually. When the particle size is large enough, the combustion efficiency reaches a critical value, and when the combustion efficiency is lower than the value, the aluminum particles will not be able to sustain combustion. With the increase of the steam inlet diameter, the pressure of the combustion chamber increases, the flow velocity of the combustion chamber reduces, the average combustion time of the aluminum particles increases and the combustion efficiency increases.

Acknowledgments: This work was supported by the National Natural Science Foundation of China (grant No. 51406231). 
Author Contributions: Xianhe Chen and Zhixun Xia conceived and designed the numerical study; Xianhe Chen and Liya Huang contributed analysis tools; Xianhe Chen performed the numerical simulations under the supervision of Zhixun Xia and Likun Ma; Xianhe Chen analyzed the data with the comments from Zhixun Xia and Likun Ma; Xianhe Chen wrote the paper under the supervision of Liya Huang and Likun Ma; Xianhe Chen and Liya Huang gave comments and modified the paper.

Conflicts of Interest: The authors declare no conflict of interest.

\section{Nomenclature}

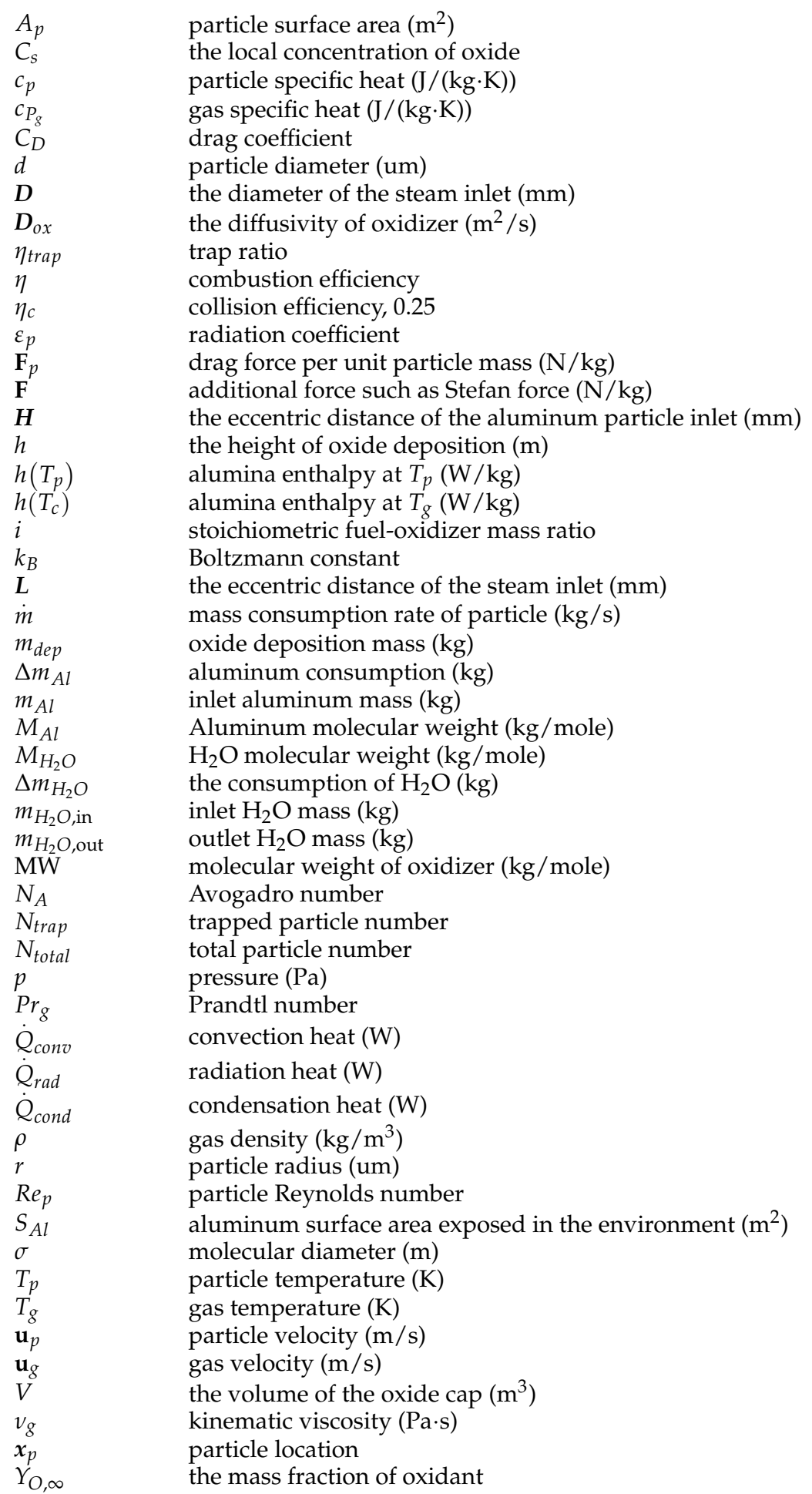




\section{References}

1. Mercati, S.; Milani, M.; Montorsi, L.; Paltrinieri, F. Design of the steam generator in an energy conversion system based on the aluminum combustion with water. J. Appl. Energy 2012, 97, 686-694. [CrossRef]

2. Daniel, F.W.; Christopher, P.C.; Eagle, W.E. Quantifying unmanned undersea vehicle range improvement enabled by aluminum-water power system. J. Propul. Power 2013, 29, 675-685.

3. Daniel, F.W.; Christopher, P.C. Modeling a hybrid Rankine-cycle/fuel-cell underwater propulsion system based on aluminum water combustion. J. Power Sources 2013, 221, 272-283.

4. Daniel, F.W.; Christopher, P.C. Estimating the neutrally buoyant energy density of a Rankine-cycle/fuel-cell underwater propulsion system. J. Power Sources 2014, 248, 714-720.

5. Sundaram, D.S.; Yang, V.; Huang, Y.; Risha, G.A.; Yetter, R.A. Effects of particle size and pressure on combustion of nano-aluminum particles and liquid water. Combust. Flame 2013, 160, 2251-2259. [CrossRef]

6. Connell, T.L.; Risha, G.A.; Yetter, R.A.; Young, G.; Sundaram, D.S.; Yang, V. Combustion of alane and aluminum with water for hydrogen and thermal energy generation. Proc. Combust. Inst. 2011, 33, 1957-1965. [CrossRef]

7. Sabourina, J.L.; Risha, G.A.; Yetter, R.A.; Son, S.F.; Tappan, B.C. Combustion characteristics of nanoaluminum, liquid water, and hydrogen peroxide mixtures. Combust. Flame 2008, 154, 587-600. [CrossRef]

8. Greatrix, D. Numerical evaluation of the use of aluminum particles for enhancing solid rocket motor combustion stability. Energies 2015, 8, 1195-1215. [CrossRef]

9. Miller, T.F.; Walter, J.L.; Kiely, D.H. A next-generation AUV energy system based on aluminum-seawater combustion. In Proceedings of the 2002 Workshop on Autonomous Underwater Vehicles, San Antonio, TX, USA, 21-21 June 2002.

10. Miller, T.F.; Herr, J.D. Green Rocket Propulsion by Reaction of $\mathrm{Al}$ and $\mathrm{Mg}$ Powders and Water. In Proceedings of the 40th AIAA/ASME/SAE/ASEE Joint Propulsion Conference and Exhibit, American Institute of Aeronautics and Astronautics, Fort Lauderdale, FL, USA, 11-14 July 2004.

11. Corcoran, A.; Mercati, S.; Nie, H.; Milani, M.; Montorsi, L.; Dreizin, E.L. Combustion of fine aluminum and magnesium powders in water. Combust. Flame 2013, 160, 2242-2250. [CrossRef]

12. Beckstead, M.W. Correlating Aluminum Burning Times. Combust. Explos. Shock Waves 2005, 41, 533-546. [CrossRef]

13. Sundaram, D.S.; Yang, V. Combustion of micron-sized aluminum particle, liquid water, and hydrogen peroxide mixtures. Combust. Flame 2014, 161, 2469-2478. [CrossRef]

14. Sundaram, D.S.; Yang, V.; Zarko, V.E. Combustion of Nano Aluminum Particles (Review). Combust. Explos. Shock Waves 2015, 51, 173-196. [CrossRef]

15. Gill, R.J.; Badiola, C.; Dreizin, E.L. Combustion times and emission profiles of micron-sized aluminum particles burning in different environments. Combust. Flame 2010, 157, 2015-2023. [CrossRef]

16. Lim, J.; Yang, H.; Yoon, W. Burning and Ignition Characteristics of Single Aluminum and Magnesium Particle. In Proceedings of the 46th AIAA/ASME/SAE/ASEE Joint Propulsion Conference \& Exhibit, Nashville, TN, USA, 25-28 July 2010.

17. Schoenitz, M.; Mohan, S.; Chen, C.; Dreizin, E.L. Oxidation and Ignition of Aluminum Particles in the Presence of Water Vapor. In Proceedings of the 44th AIAA/ASME/SAE/ASEE Joint Propulsion Conference \& Exhibit, Hartford, CT, USA, 21-23 July 2008.

18. Ermoline, A.; Yildiz, D.; Dreizin, E.L. Model of heterogeneous combustion of small particles. Combust. Flame 2013, 160, 2982-2989. [CrossRef]

19. Mohan, S.; Trunov, M.A.; Dreizin, E.L. On possibility of vapor-phase combustion for fine aluminum particles. Combust. Flame 2009, 156, 2213-2216. [CrossRef]

20. Bojko, B.T.; DesJardin, P.E.; Washburn, E.B. Modeling Transitional Burning Modes of Aluminum Particles. In Proceedings of the 8th US National Combustion Meeting, Park City, UT, USA, 19-22 May 2013.

21. Washburn, E.B.; Trivedi, J.N.; Catoire, L.; Beckstead, M.W. The Simulation of the Combustion of Micrometer-Sized Aluminum Particles with Steam. Combust. Sci. Technol. 2008, 180, 1502-1517. [CrossRef]

22. Puri, P. Multi Scale Modeling of Ignition and Combustion of Miro and Nano Aluminum Particles. Ph.D. Thesis, The Pennsylvania State University, State College, PA, USA, 2008.

23. Yetter, R.A.; Risha, G.A.; Son, S.F. Metal particle combustion and nanotechnology. Proc. Combust. Inst. 2009, 32, 1819-1838. [CrossRef] 
24. Najjar, F.M.; Ferry, J.P.; Haselbacher, A.; Balachander, S. Simulations of Solid-Propellant Rockets: Effects of Aluminum Droplet Size Distribution. J. Spacecr. Rocket. 2006, 43, 1258-1270. [CrossRef]

25. Boyd, E.; Houim, R.; Kuo, K.K. Ignition and Combustion of Nickel Coated and Uncoated Aluminum Particles in Hot Post-Flame Environment. In Proceedings of the 45th AIAA/ASME/SAE/ASEE Joint Propulsion Conference \& Exhibit, Denver, CO, USA, 2-5 August 2009.

26. Rosenband, V. Thermo-mechanical aspects of the heterogeneous ignition of metals. Combust. Flame 2004, 137, 366-375. [CrossRef]

27. Huang, Y.; Risha, G.A.; Yang, V.; Yetter, R.A. Flame Propagation in Bimodal Nano/Micro-Sized Aluminum Particles/Air Mixtures. In Proceedings of the 44th AIAA Aerospace Sciences Meeting and Exhibit, Reno, NV, USA, 9-12 January 2006.

28. Eisenreich, N.; Fietzek, H.; del MarJuez-Lorenzo, M.; Kolarik, V.; Koleczko, A.; Weiser, V. On the mechanism of low temperature oxidation for aluminum particles down to the nano-scale. Propellants Explos. Pyrotech. 2004, 29, 137-145. [CrossRef]

29. George, P.; DesJardin, P.E. Effects of Heterogenous of surface reactions on the ignition of aluminum particles. In Proceedings of the 42nd AIAA Aerospace Sciences Meeting and Exhibit, AIAA 2004-790, Reno, NV, USA, 5-8 January 2004.

(C) 2016 by the authors; licensee MDPI, Basel, Switzerland. This article is an open access article distributed under the terms and conditions of the Creative Commons Attribution (CC-BY) license (http://creativecommons.org/licenses/by/4.0/). 